\title{
Parameter identification for anisotropic plasticity model using digital image correlation
}

\section{Comparison between uni-axial and bi-axial tensile testing}

\author{
David Lecompte* - Steven Cooreman** - Sam Coppieters** \\ John Vantomme* - Hugo Sol*** — Dimitri Debruyne**
}

* Department of Materials and Construction

Royal Military Academy, Avenue de la Renaissance 30, 1000 Brussels, Belgium

\{david.lecompte, john.vantomme\}@rma.ac.be

** Department of Mechanical Engineering

Technical University KaHo Sint-Lieven, Gebroeders Desmetstraat 1, 9000 Ghent, Belgium

\{steven.cooreman, dimitri.debruyne,sam.coppieters\}@kahosl.be

*** Department of Mechanics of Materials and Constructions

Vrije Universiteit Brussel, Pleinlaan 2, 1050 Brussels, Belgium

hugos@vub.ac.be

ABSTRACT. The basic principle of the described procedure for plastic material identification is the generation of a complex and heterogeneous deformation field, which is measured by digital image correlation (DIC) and compared to Finite Element (FE) simulations. In this paper two tests for the identification of the hardening behaviour and the yield locus of DCO6 steel are compared: a uni-axial test on a perforated rectangular specimen and a bi-axial tensile test on a cruciform specimen. The work hardening of the material is assumed to be isotropic and the yield locus is modelled by the anisotropic Hill48 criterion. The identification results for the different material parameters, based on both the uni-and the bi-axial test, are discussed and show a significant agreement.

RÉSUMÉ. Le principe de la méthode décrite pour l'identification paramétrique d'un modèle plastique est de générer un champ de déformation complexe, mesurée à l'aide de la corrélation d'image et comparée à un champ de déformation calculé par éléments. Cette publication traite de la comparaison de deux tests pour l'identification de la loi de durcissement et la surface de plasticité d'un acier DC06 : un test uniaxial sur une éprouvette rectangulaire trouée et un test biaxial sur une éprouvette cruciforme. Le durcissement du matériau est décrit par la loi de Swift et la surface de plasticité par le critère anisotropique Hill48. Les résultats de l'identification, basés sur les tests uniaxial et biaxial, sont discutés et s'avèrent similaires.

KEYWORDS: digital image correlation, material identification, inverse modelling.

MOTS-CLÉS : corrélation d'images, identification de comportement de matériaux, modélisation inverse.

DOI:10.3166/EJCM.18.393-418 (C) 2009 Lavoisier, Paris

EJCM - 18/2009. Pictures and finite elements, pages 393 to 418 


\section{Introduction}

The motivation of the study of metals and their plastic mechanical behaviour is coupled to the industrial demand for lighter parts with higher mechanical resistance. The manufacturing process of these parts is a complex matter and the final quality of the product is coupled to a number of parameters. The shape and size of the processing tools, the applied loads, the obtained displacements, the lubrication conditions, the thickness of the sheet, the material anisotropy and elasto-plastic properties are just a few of the variables influencing the resulting product. Possible additional problems such as springback, wrinkles and earing behaviour can occur and should preferably be predictable. Therefore, accurate modelling of the different processes is a very important and indisputably cost saving activity.

The numerical simulation of sheet metal forming processes in the automotive or aerospace industry has considerably evolved concurrently with computer performance and the development of computational methods like the Finite Element Method (FEM). It has proven to reduce tool costs in the design stage and to optimize existing processes. The behavioural laws implemented in these simulation codes not only need to be thermodynamically acceptable and fulfil the general mechanical principles, they have to be identifiable as well. It should therefore be possible to determine the inherent model parameters, based on a number of more or less complex mechanical tests. These parameters need to be identified so as to enable sufficiently realistic predictions of actual material behaviour.

The elasto-plastic constitutive laws represent an important class of models used for the simulation of metallic structures. They are all based on:

- a yield criterion, which determines the multi-axial stress state at which plastic deformation or yielding occurs;

- a flow rule, offering a relationship between the components of the strain rate and the stress;

- a hardening law, describing the evolution of the initial yield stress during plastic deformation.

Two types of elasto-plastic laws exist. On the one hand there are the models based on an approximation of experimental data by an analytical function for the description of the yield function. These models are said to be "phenomenological". On the other hand, models in which the elastic limit is calculated based on the crystallographic structure of the material can be considered as well. These models are called "texture-based" or "micro-macro". For the latter type of models, instead of mechanical tests, texture measurements by X-ray diffraction are performed in order to identify the initial yield surface (Flores, 2006). This polycrystalline analysis predicts the relation between macroscopic stress and plastic deformation.

The use of these texture-based models, however, is computationally expensive. The usual way to achieve faster solutions is to define explicit yield functions. In this paper, only the latter type of models is considered. The main reason to do so, is their 
availability in most commercial simulation softwares. However, attention should be drawn to the fact that the validity of phenomenological models is limited to situations that are comparable to the range of experiments on which they are based (Boogaard, 2002).

Accurate modelling is naturally coupled to an accurate identification of the inherent model parameters. Several tests (uni-axial tensile test, plane strain test, shear test, equi-bi-axial test) have been developed for the homogeneous identification of yield criteria and hardening model parameters. The term "homogeneous" is an indication of the nature of the obtained deformations. This is an assumption, which is however not always verified (Khalfallah, 2002). It is therefore more efficient to take into account possible heterogeneous straining. This is possible by the use of a full-field measurement technique coupled to inverse modelling.

The use of inverse modelling, in its most general sense (i.e. not necessarily based on full field measurements), in the area of metal forming processes is of a recent date. In the first examples of the application of an inverse modelling strategy, standard experiments like tensile tests on axi-symmetric specimens were used and compared to FE-simulated results (Mahnken et al., 1997; 1999) and (Bruhns et al., 1999). Other authors make use of notched cylindrical bars (Springmann et al., 2005), uni-axial compression tests (Lam et al., 1998), torsion tests (Lam et al., 1998; Gavrus et al., 1996) or cyclic bending tests (Yoshida et al., 2003). In the cited references, the parameters of a selected plastic model are estimated by minimizing a weighted sum of squared differences between measured and calculated strains or displacements and the applied loads.

Instead of using only simple practically homogeneous tests, several authors have performed experiments leading to non-uniform stress and strain fields. The idea residing in this approach is to make the simultaneous identification of a number of model parameters possible based on a single test. Related articles using nonconventional specimen geometries can be found in (Kajberg et al., 2004; Meuwissen 1998; Khalfallah, 2002; Mahnken et al., 1996; Grédiac et al., 2006) and (Pannier et $a l ., 2006)$ By using non-standard experiments exhibiting inhomogeneous stress and strain fields, a more complete assessment of the model performance can be obtained. This assessment is even further enhanced if local or field information is measured in addition to global or boundary information.

The elasto-plastic material model considered in this work, is based on an additive decomposition of the total strain increments into an elastic and a plastic part, coupled to the assumption of rate independent associative plasticity and using a large strains description. The hardening of the material is assumed to be isotropic and it is modelled by a Swift hardening law. The yield locus on the other hand is modelled by the orthotropic quadratic Hill48 yield criterion. These assumptions, together with the assumption of plane stress, yield six independent parameters to be identified. 
To this end, the measured loads are implemented as boundary conditions in the FE-model of the experiments and the different strain components obtained by digital image correlation are compared to the simulated values. Two types of tensile tests using more or less complex specimen geometries are proposed for the identification of the hardening behaviour and the yield surface of an interstitial free (IF) DC06 steel: a uni-axial tensile test using a perforated rectangular specimen and a bi-axial tensile test performed on a perforated cruciform specimen. Both tests are compared based on the values of the obtained material parameters and based on the convergence behaviour of the corresponding iterative procedure. For each experiment, the difference between the experimental and numerical strains $\left(\varepsilon_{\mathrm{x}}, \varepsilon_{\mathrm{y}}\right.$ and $\varepsilon_{\mathrm{xy}}$ ) is minimized in a least squares sense by updating the values of the different material parameters simultaneously. The sensitivities used to obtain the parameter updates are determined by finite differences, using small parameter perturbations. The applied optimization routine, is based on a constrained Newton-type algorithm.

Paragraph two gives a description of both considered experimental set-ups: the uni-axial and the bi-axial tensile test. Paragraph three contains a brief description of the digital image correlation measurement technique. Paragraph four describes the applied numerical model. Paragraph five discusses homogeneous elasto-plastic material identification and paragraph six discusses the inverse modelling procedure, the numerical aspects of the optimization routine and the sensitivity analysis used. Finally, paragraph six evaluates the parameter identification results based on both heterogeneous experiments and compares them to the results obtained by standard homogeneous material tests.

\section{Experimental set-ups}

\subsection{Bi-axial tensile test}

Different experimental techniques and specimens have been used to produce biaxial stress states. These techniques may be mainly classified into two categories (Zouani, 1996): (i) tests using a single loading system and (ii) tests using two or more independent loading systems. In the first category the bi-axial stress ratio depends on the specimen geometry - their main disadvantage - whereas in the second category it is specified by the applied load magnitude. Examples of the first category are bending tests on cantilever beams, anticlastic bending of rhomboidal shaped plates and bulge tests. Examples of the second category are thin-walled tubes subjected to a combination of tension/compression with torsion or internal/external pressure, and cruciform specimens under bi-axial loading (Dawicke, 2000). The most direct technique to create bi-axial stress states consists in applying in-plane loads along two perpendicular arms of cruciform specimens. The use of hydraulic actuators represents a very versatile technique for the application of the loads. The main difference between the existing techniques is the use of one or two actuators per loading direction. One actuator per loading direction (Chaudonneret, 1977) will 
cause movements of the centre of the specimen causing a side bending of the specimen. This results in undesirable non-symmetric strains. Systems with four actuators (Makinde, 1992) with a closed-loop servo control using the measured loads as feedback system, allow keeping the centre of the specimen in the same position.

The plane bi-axial test device using cruciform specimens developed at the Vrije Universiteit Brussel has four independent servo-hydraulic actuators with an appropriate control unit to keep the centre of the specimen explicitly still. The device (Figure 1) has a capacity of $100 \mathrm{kN}$ in both perpendicular directions, but only in tension. As no cylinders with hydrostatic bearing were used, failure or slip in one arm of the specimen will result in sudden radial forces which could seriously damage the servo-hydraulic cylinders and the load cells. To prevent this, four hinges were used to connect the specimen to the load cells and the servo-hydraulic cylinders to the test frame. Using hinges for each loading direction however results in an unstable situation in compression and consequently only tension loads can be performed.

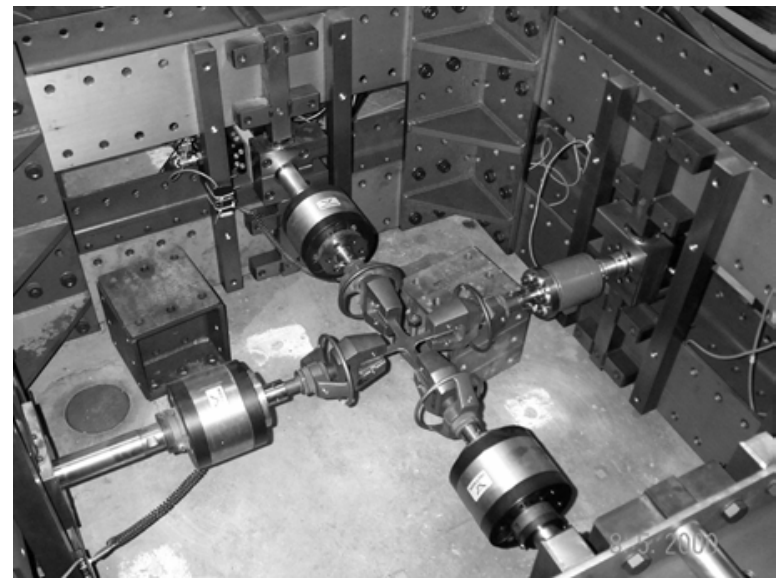

Figure 1. Plane bi-axial test device for cruciform specimens

In an ideal situation no displacement of the centre point of the specimen should be observed. However, even when using four actuators, a small displacement might always occur in a real situation. This problem can be solved by quantifying the small load difference and using this as a control signal (Smits, 2006).

The geometry of the material specimen is shown in Figure 2. The specimen has a thickness of $0.8 \mathrm{~mm}$. The specimen's arms are in alignment with the rolling (RD) and transverse direction (TD) of the metal sheet (see Figure 2). The shaded area indicated in Figure 2 is the zone in which the experimentally determined strains are 
compared to the numerical strains (the strains are compared in the Gauss points of the elements of the FE model).

During the test, the force on the 4 arms is increased up to approximately $4.25 \mathrm{kN}$. The unknown parameters are determined iteratively by comparing the experimentally measured and the numerically computed strain fields at 7 different loading steps, namely $3511 \mathrm{~N}, 3755 \mathrm{~N}, 4019 \mathrm{~N}, 4082 \mathrm{~N}, 4136 \mathrm{~N}, 4219 \mathrm{~N}$ and $4253 \mathrm{~N}$.

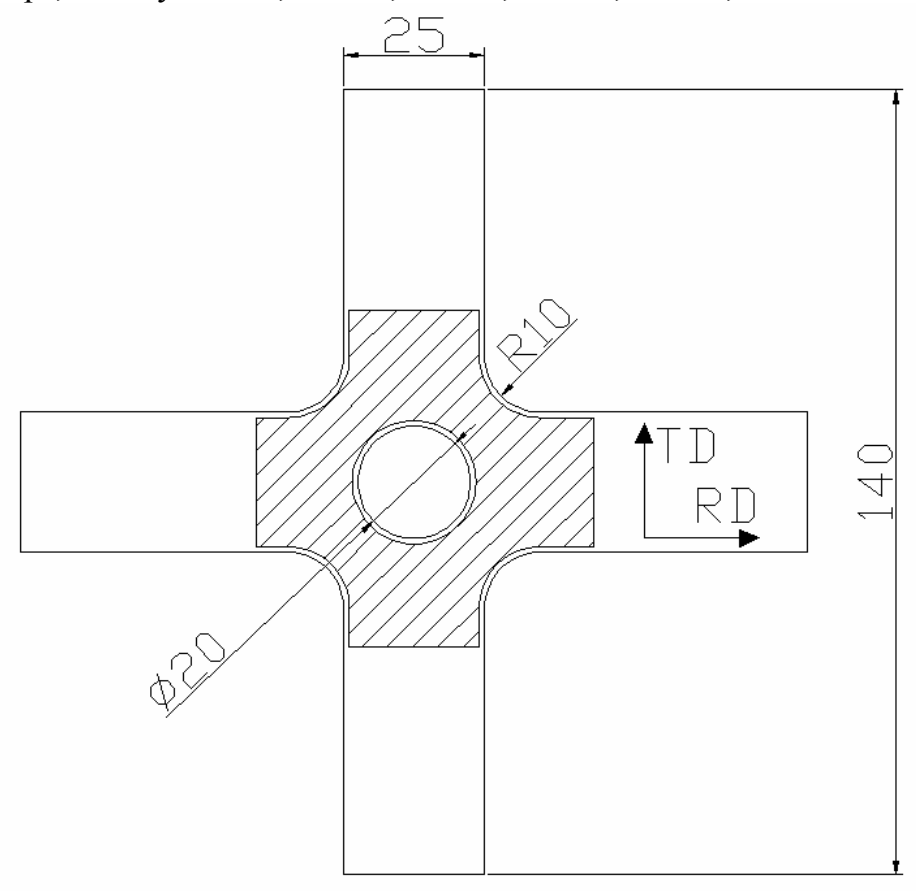

Figure 2. Geometry of the perforated cruciform specimen

\subsection{Uni-axial tensile test}

The second experiment consists of a uni-axial tensile test on the perforated specimen shown in Figure 3. The specimen has again a thickness of $0.8 \mathrm{~mm}$. The tensile direction is rotated by $45^{\circ}$ with respect to the in plane material directions. The shaded area indicated in Figure 3 is the zone in which the experimentally "measured" strains are compared to the numerical strains.

During the test the force is increased up to approximately $7.65 \mathrm{kN}$. Again the strain data from 7 load steps is used to identify the unknown material parameters: $6318 \mathrm{~N}, 6543 \mathrm{~N}, 6763 \mathrm{~N}, 6987 \mathrm{~N}, 7217 \mathrm{~N}, 7432 \mathrm{~N}$ and $7656 \mathrm{~N}$. 


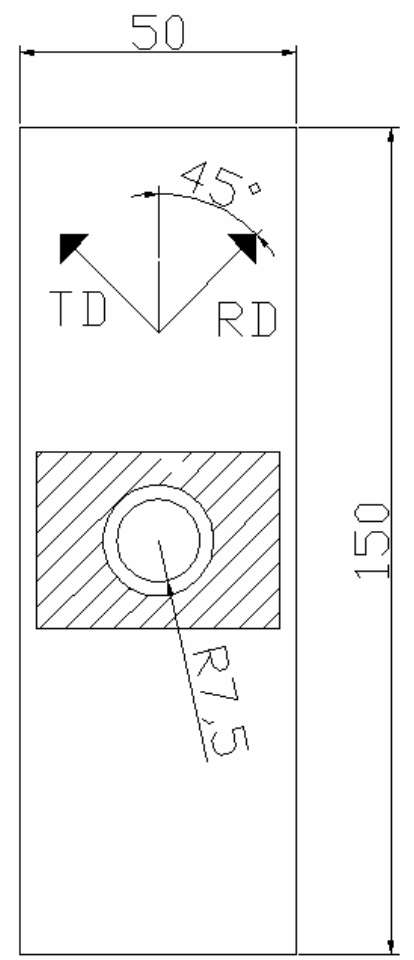

Figure 3. Geometry of the uni-axial, perforated specimen

\section{Digital image correlation}

Displacement and strain determination used on the perforated specimens is performed by digital image correlation (DIC). This technique allows studying qualitatively as well as quantitatively the mechanical behaviour of materials under certain loading conditions and has been used in various technological domains. The DIC technique has been developed in the 80 's and has since then extensively been evaluated (Knauss et al., 2003; Schreier et al., 2000; Sutton et al., 1988) and improved (Bruck et al., 1989; Sutton et al. 1986, Cheng et al. 2002, Yoneyama et al., 2006). However, the fundamental principles of the method remain unchanged and are well described by (Peters and Ranson, 1982; Sutton et al., 1983 and Chu et al. 1985).

Each picture taken with a CCD camera corresponds to a different load step. The cameras used in the current set-up use a 1392x1040 pixel gray level 12-bit CCD sensor. Two images of the specimen at different states of deformation are compared by means of a correlation window or an image subset. The image correlation routine allows locating every subset of pixels in the initial image in the deformed image by 
means of a classic correlation function using the sum of the squared differences of the pixel values. The displacement result, expressed in the centre point of the subset, is an average of the displacements of the pixels inside the subset. The step size defines the number of pixels over which the subset is shifted in $\mathrm{x}$ - and $\mathrm{y}$ - direction in the selected image to calculate the next result. The size of a subset can be for example 9x9, 11 x11, 13x13 pixels etc.; the step size can be 1, 2, 3 pixels etc.

For the actual tests a subset size of 19 pixels and a step size of 5 pixels is used. In the available commercial DIC-systems the subset size is identical throughout the entire image. This means that once the subset size is chosen, it remains identical during the correlation calculation. The size of the subset depends on the type of deformation field to be expected. When dealing with homogeneous deformation (constant displacement gradients), the subset size should be as big as possible to enable noise filtering and thereby smoothing of the displacement data. However, in the case of heterogeneous deformations (variable displacement gradients), the subset size should be a trade-off between smearing out the displacement data (noise filtering) and correlation problems. When using large subsets, the displacement data is homogenized in an area that does not necessarily correspond to the heterogeneous character of the deformation field. When using small subsets, the grey value pattern is not always unique enough to avoid problems during the correlation calculation

The choice of a 19x19 pixels subset size in this study is a fair compromise between the previously cited arguments. The step size on the other hand only determines the resolution of available displacement data. The smaller the step size, the larger the number of displacement data points and the longer the correlation calculation time. The chosen step size is a compromise between a fair CPU-time and the possibility to smoothen the displacement data within a given strain window. A strain window is defined by the number of identified displacement points.

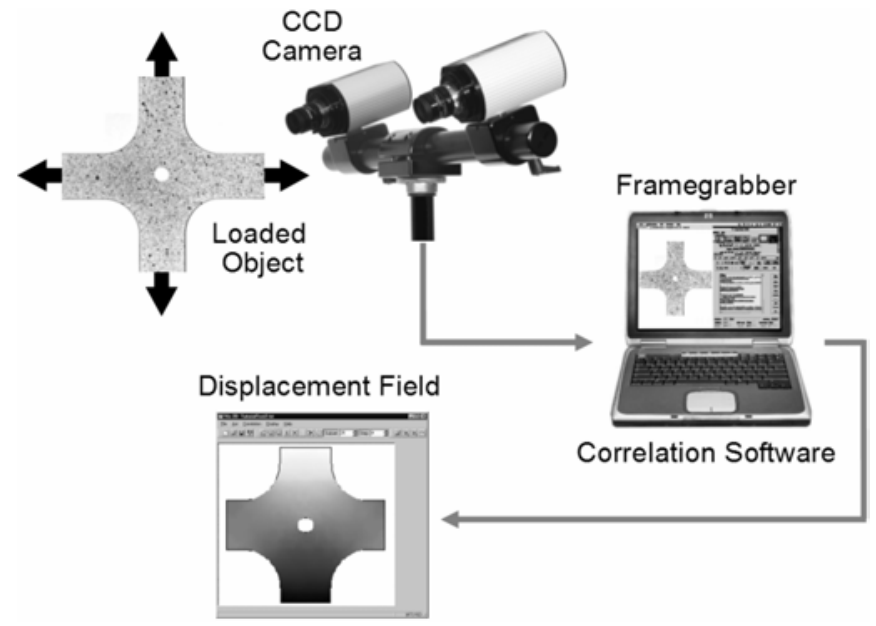

Figure 4. Digital image correlation technique 
Figure 4 depicts the sequence of taking a picture of an object before and after loading, storing the images onto a PC through a frame grabber, performing the correlation of both images - i.e. locating the different undeformed subsets in the deformed image - and finally calculating the corresponding displacement of the centers of the subsets, which finally yields the desired displacement field.

The strain field is calculated by numerical differentiation of the smoothened displacement field (Lecompte, 2007). In this study the experimental and FEcalculated strains are compared as being the responses of the system to the boundary conditions. This means that the experimental strains have to be derived from the measured displacement field. As a step size of 5 pixels is used, an experimental displacement value is available every 5 pixels in both horizontal and vertical direction. The FE-strains are calculated at the Gauss points located in the FE-mesh elements. The objective is to calculate the experimental strains at the same location. A bilinear interpolation function is therefore fitted onto a square region of $5 \times 5$ data points (i.e. strain window size) around the coordinates of the Gauss-points in the experimental displacement data field. The choice of a region containing $5 \times 5$ data points is based on a trade-off between too much smoothing when a larger region is used and a higher noise influence when a smaller region is used. Once the analytical curve fit expression of the surface of the region is determined for both the horizontal and the vertical displacement components, it can simply be differentiated at the considered location in both directions, yielding the different strain components. When the elements of the FE-mesh contain only one Gauss point, which is the case in the present study, the strain values will be compared at a number of locations equal to the number of elements.

\section{Numerical model}

The numerical strain fields are computed with the commercial FE package Abaqus/Standard (Abaqus Inc. version 6.6). For both experiments, the specimen is modelled with S4R elements (linear shell elements with reduced integration), which is a valid representation since the out-of-plane shear stresses will be negligible. The average mesh size in the area of interest is about $1 \mathrm{~mm}$ for the cruciform specimen and circa $0.75 \mathrm{~mm}$ for the uni-axial specimen. The constitutive model, applied in Abaqus/Standard, is a hypoelastic-plastic formulation, assuming that the total logarithmic strain rate $\mathrm{D}$ can be additively split into an elastic and a plastic part:

$$
\mathrm{D}=\mathrm{D}^{\mathrm{el}}+\mathrm{D}^{\mathrm{pl}}
$$

Moreover an associated flow rule is applied, assuming normality of the plastic strain rate to the yield surface:

$$
\mathrm{D}^{\mathrm{pl}}=\dot{\lambda} \frac{\partial \Phi}{\partial \sigma}
$$


with $\dot{\lambda}$ the plastic multiplier, $\Phi$ the yield surface and $\sigma$ the Cauchy stress tensor. The material is assumed to be elastically isotropic and plastically orthotropic. The elastic constants are evaluated from standard tensile tests. A Young's modulus E of $183 \mathrm{GPa}$ and a Poisson coefficient $v$ of 0.35 were found. These values are considered to be known. This implies that the elastic material properties are not identified together with the other parameters. As the elastic strains for metals are very small, they can only be measured with very limited accuracy by digital image correlation. It is therefore chosen not to consider them as additional unknowns.

The yield surface is represented by the Hill48 yield criterion. Since plane stress conditions were assumed, the Hill 48 yield criterion can be written as:

$$
(\mathrm{G}+\mathrm{H}) \sigma_{\mathrm{xx}}^{2}+(\mathrm{F}+\mathrm{H}) \sigma_{\mathrm{yy}}^{2}-2 H \sigma_{\mathrm{xx}} \sigma_{\mathrm{yy}}+2 \mathrm{~N} \sigma_{\mathrm{xy}}^{2}-\sigma_{\mathrm{eq}}^{2}=0
$$

in which the indices $\mathrm{x}$ and $\mathrm{y}$ indicate both orthotropic axes, with $\sigma_{\text {eq }}$ the equivalent stress and $\mathrm{G}+\mathrm{H}=1$. The hardening behaviour is described by a Swift law:

$$
\sigma_{\mathrm{eq}}=\mathrm{K}\left(\varepsilon_{0}+\varepsilon_{\mathrm{eq}}^{\mathrm{pl}}\right)^{\mathrm{n}}
$$

with $\mathrm{K}$ the deformation resistance, $\varepsilon_{0}$ the pre-strain value, $\varepsilon_{\mathrm{eq}}^{\mathrm{pl}}$ the equivalent plastic strain and $\mathrm{n}$ the hardening exponent. It should be noted that neither kinematic hardening nor strain rate dependency are considered. Thus, a total of 6 material parameters have to be identified: $\mathrm{n}, \mathrm{K}, \varepsilon_{0}, \mathrm{~F}, \mathrm{H}$ and $\mathrm{N}$. The initial parameter values are estimated as: $\mathrm{n}=0.3, \mathrm{~K}=600 \mathrm{MPa}, \varepsilon_{0}=0.005, \mathrm{~F}=\mathrm{G}=\mathrm{H}=0.5$ and $\mathrm{N}=1.5$ (i.e. assumption of isotropic behaviour).

\section{Homogeneous identification}

The orthogonal coordinate system defined for rolled material is based on three principal axes of that material, i.e. the rolling direction (RD), the transverse direction (TD) and the normal direction (ND). The local xyz-coordinate system for a tensile specimen cut out of a plate material is defined by the angle between the rolling direction and the specimens longitudinal axis. For a sheet metal sample, the $\mathrm{x}$ - and $\mathrm{y}$-axis lie in the material plane and the $\mathrm{z}$-axis is perpendicular to it.

Traditionally the parameters of the hardening law are determined based on a tensile test, performed on a specimen cut out in the rolling direction. The parameters of the Hill48 yield criterion on the other hand are determined by the Lankford coefficients $r_{0^{\circ}}, r_{45^{\circ}}$ and $r_{90^{\circ}}$. These coefficients represent the ratio between the transversal plastic strain rate and the through thickness plastic strain rate occurring during a tensile test in respectively the $0^{\circ}, 45^{\circ}$ and $90^{\circ}$ direction from the rolling direction. As the thickness strain cannot easily be measured, it is calculated using the assumption of volume conservation during plastic deformation. It can be shown 
that the relations between the Lankford coefficients and the different 2D Hill48 parameters reduce to:

$$
\begin{aligned}
& \mathrm{r}_{0^{\circ}}=\frac{\dot{\varepsilon}_{\mathrm{y} / 0^{\circ}}^{\mathrm{pl}}}{\dot{\varepsilon}_{\mathrm{z}}^{\mathrm{pl}}}=\frac{\dot{\varepsilon}_{\mathrm{y}}^{\mathrm{pl}}}{\dot{\varepsilon}_{\mathrm{z}}^{\mathrm{pl}}}=\frac{\mathrm{H}}{\mathrm{G}} \\
& \mathrm{r}_{90^{\circ}}=\frac{\dot{\varepsilon}_{\mathrm{y} / 90^{\circ}}^{\mathrm{pl}}}{\dot{\varepsilon}_{\mathrm{z}}^{\mathrm{pl}}}=\frac{\dot{\varepsilon}_{\mathrm{x}}^{\mathrm{pl}}}{\dot{\varepsilon}_{\mathrm{z}}^{\mathrm{pl}}}=\frac{\mathrm{H}}{\mathrm{F}} \\
& \mathrm{r}_{45^{\circ}}=\frac{\dot{\varepsilon}_{\mathrm{y} / 45^{\circ}}^{\mathrm{pl}}}{\dot{\varepsilon}_{\mathrm{z}}^{\mathrm{pl}}}=\frac{2 \mathrm{~N}-\mathrm{F}-\mathrm{G}}{2(\mathrm{~F}+\mathrm{G})}
\end{aligned}
$$

As the equivalent yield stress is equal to the stress in a uni-axial tensile test in the rolling direction, it can be stated that $\mathrm{H}+\mathrm{G}=1$.Together with this relation, equations 5-7 lead to a fully determined system of equations allowing to determine the four unknown parameters $\mathrm{F}, \mathrm{G}, \mathrm{H}$ and $\mathrm{N}$.

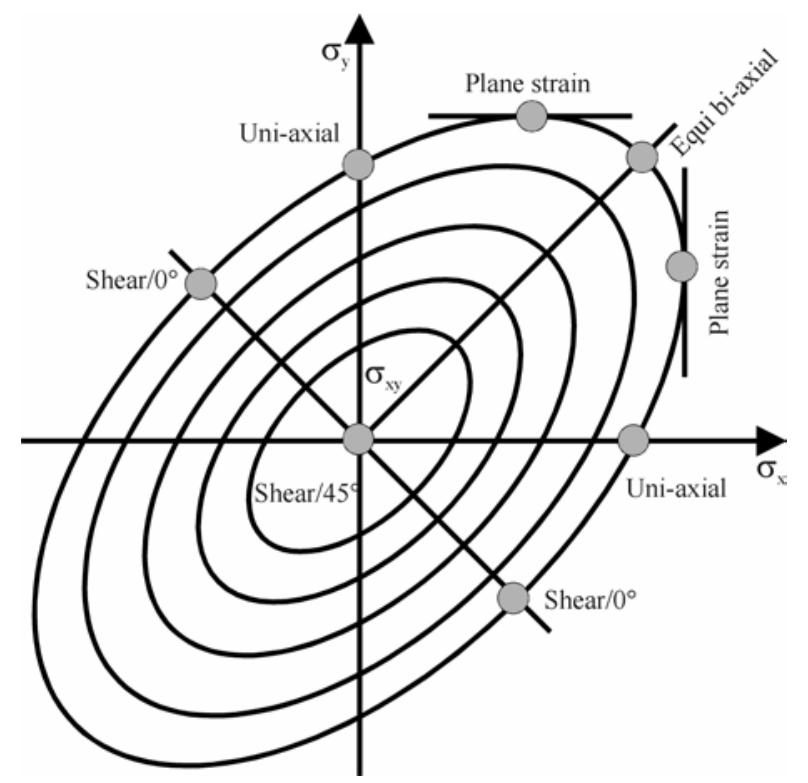

Figure 5. Different stress states on the initial yield surface expressed in $\sigma_{x}-\sigma_{y}-\sigma_{x y}-$ space defined by the axes of orthotropy

Another possibility to identify the parameters of the yield criterion is by fitting the expression on a number of experimentally obtained stress states. To this end a number of standard tests can be performed: uni-axial tensile tests in the $0^{\circ}$ and $90^{\circ}$ 
direction from the rolling direction; plane strain tensile test; in plane equi-bi-axial tensile test; pure shear test. The stress states corresponding to these tests can be represented in the $\sigma_{x}-\sigma_{y}-\sigma_{x y}-$ space (Figure 5). The axes correspond respectively to the stress in the rolling direction, the stress in the transverse direction and the shear stress. These stresses are not necessarily the principal stresses. This is only the case when the shear component is absent. Information about the experimental equipment that can be used to attain the different stress states can be found in (Flores, 2006). Results of this type of initial yield surface identification are discussed in (Vegter, 2003 and Flores, 2006). All of the performed experiments in these references possess the same property: the obtained strain field has to be as homogeneous as possible to allow a straightforward determination of the stress and the strain values. The hypothesis of homogeneity however, is not always verified. In the next paragraph, a method is proposed based on the coupling between Finite Element simulation and full-field surface displacement data. In this case the homogeneity of deformation is not longer needed, it is even avoided.

\section{Inverse modelling}

\subsection{Introduction}

A so-called "direct" problem is the classical problem where, in the field of mechanical engineering, a given process or experiment is simulated in order to obtain the geometry of the considered object and the stress-strain distribution in the final configuration as well as its evolution during the process of deformation. The success of such an analysis largely depends on the reliability of the applied constitutive models and on the accuracy of the estimates of the parameters in these models.

Most standardized methods for the determination of constitutive material model parameters are based on the use of test specimens with a well-defined standardized geometry and loading, so as to induce particular conditions on the obtained stress and strain field, which are satisfied in at least a part of the specimen. Uni-axial tensile and compression tests, plane strain tensile tests, torsion and bending tests are suchlike experiments that allow the determination of the unknown material parameters. Relatively simple analytical relations can be used accordingly to determine the unknown material parameters from the measurement of variables such as forces, torques, displacements and twist angles.

For many processes in e.g. metallurgical industry where materials are subjected to high strains and high strain rates, possibly in combination with high temperatures, the strain and stress distributions are not homogeneous at all. This implies that the use of conventional tests, with carefully designed test specimens, not always allows to correctly identify the actual material behaviour. This is why an increasing interest is found in so-called "inverse" methods, also known as "mixed numerical experimental methods", which allow taking into account complex specimen geometries and loading conditions. 


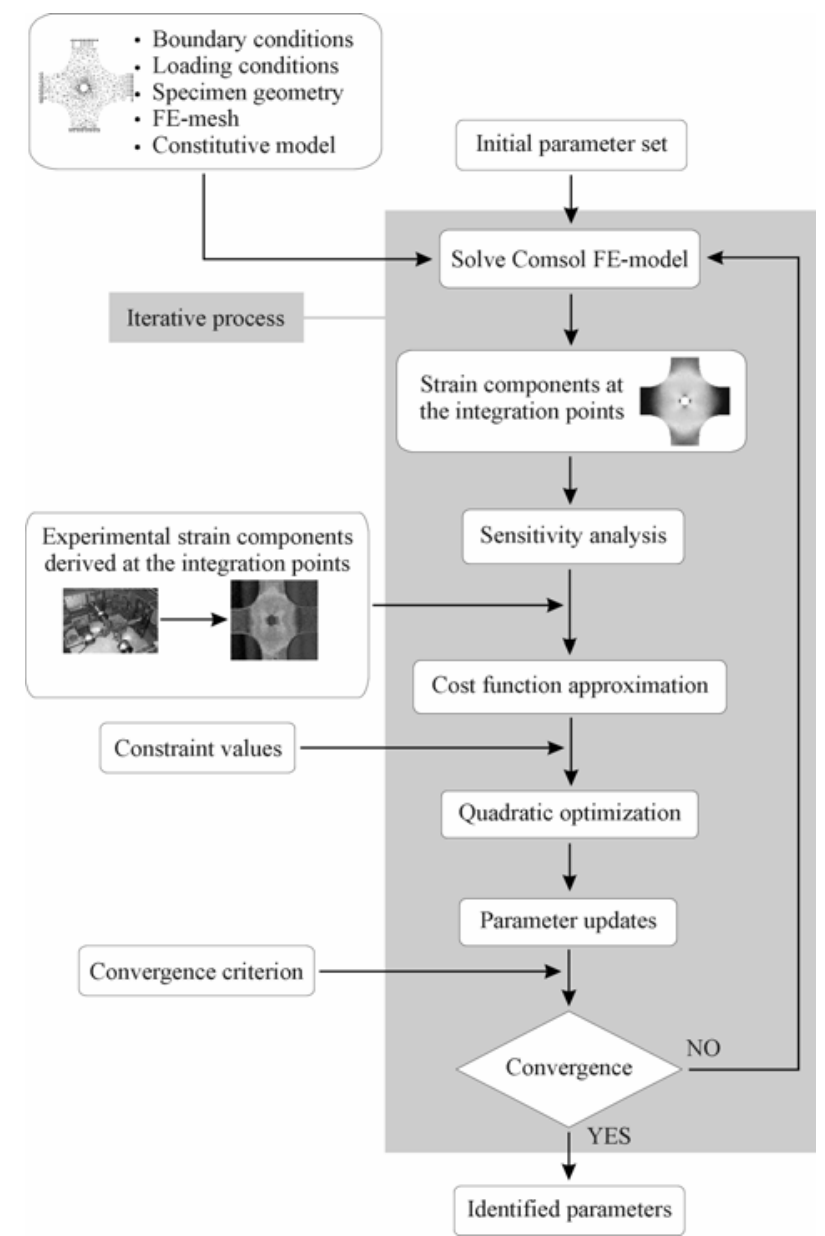

Figure 6. General flow-chart of an inverse modelling problem

Figure 6 illustrates the general concept of an inverse modelling problem in the case of mechanical parameter estimation or parameter identification. In this example a bi-axial tensile test is considered as the system and the corresponding strain field is the system's response.

\subsection{Optimisation algorithm and sensitivity calculation}

The identification of the six considered unknown material parameters is based on a Gauss-Newton optimisation method. The cost function that is minimized is expressed in terms of an unweighted least squares formulation. Expression [8] shows the form of 
cost function $\mathrm{C}(\mathrm{p})$, in which $\mathrm{p}$ is the vector of material parameters to be identified. The residuals in the function are formed by the differences between the experimental and the numerical strain components $\varepsilon_{\mathrm{x}}, \varepsilon_{\mathrm{y}}$ and $\varepsilon_{\mathrm{xy}}$ expressed numerically as well as experimentally (as explained in Section 3) in the Gauss-point of every mesh element. The index " $t$ " in expression [8] stands for the total number of elements and the index "s" stands for the total number of considered load steps.

$\mathrm{C}(\underline{p})=\sqrt{\sum_{\mathrm{j}=1}^{\mathrm{s}}\left(\sum_{\mathrm{i}=1}^{\mathrm{t}}\left(\varepsilon_{\mathrm{x}_{\mathrm{i}}}^{\text {num }}(\underline{p})-\varepsilon_{x_{\mathrm{i}}}^{\text {exp }}\right)^{2}+\left(\varepsilon_{y_{i}}^{\text {num }}(\underline{p})-\varepsilon_{y_{i}}^{\exp }\right)^{2}+\left(\varepsilon_{x y_{i}}^{\text {num }}(\underline{p})-\varepsilon_{x y_{i}}^{\text {exp }}\right)^{2}\right)_{j}}$

The necessary condition for a cost function to attain its minimum is expressed by [9]. The partial derivative of the function with respect to the different material parameters has to be zero:

$$
\frac{\partial C(\underline{p})}{\partial \underline{p}_{r}}=\frac{1}{C(\underline{p})} \sum_{j=1}^{s} \sum_{i=1}^{t}\left(\varepsilon_{x_{i}}^{\text {num }}(\underline{p})-\varepsilon_{x_{i}}^{\exp }\right) \frac{\partial \varepsilon_{x_{i}}^{\text {num }}}{\partial p_{r}}+\left(\varepsilon_{y_{i}}^{\text {num }}(\underline{p})-\varepsilon_{y_{i}}^{e x p}\right) \frac{\partial \varepsilon_{y_{i}}^{\text {num }}}{\partial p_{r}}+\left(\varepsilon_{x y_{i}}^{\text {num }}(\underline{p})-\varepsilon_{x y_{i}}^{\text {exp }}\right) \frac{\partial \varepsilon_{x y_{i}}^{\text {num }}}{\partial p_{r}}=0
$$

Expression [9] has to be written for every single unknown parameter $p_{j}$.

As no explicit relationship between the numerical strain components and the different parameters exists, it is not possible to find an analytical solution for the optimal parameter values. The problem has to be solved iteratively by updating the parameter values. Therefore, the different strain components $\varepsilon_{\mathrm{x}}^{\text {num }}, \varepsilon_{\mathrm{y}}^{\text {num }}$ and $\varepsilon_{\mathrm{xy}}^{\text {num }}$ are linearised around a given parameter set $\mathrm{p}^{\mathrm{k}}$. This is done by developing a Taylor expansion of the simulated strains around that same parameter set and limiting the expression to the linear terms. The following expression [10] for $\varepsilon_{\mathrm{x}}^{\text {num }}$ is then obtained, in which $\left(p_{j}-p_{j}^{k}\right)$ is the difference for a given parameter between the value $p_{j}^{k}$ at the working point $k$ and its new estimate $p_{j}$.

$$
\varepsilon_{\mathrm{i}}^{\text {num }}(\underline{\mathrm{p}})=\varepsilon_{\mathrm{i}}^{\text {num }}\left(\underline{\mathrm{p}}^{\mathrm{k}}\right)+\sum_{\mathrm{j}=1}^{\mathrm{m}} \frac{\partial \varepsilon_{\mathrm{i}}^{\mathrm{num}}\left(\underline{\mathrm{p}}^{\mathrm{k}}\right)}{\partial \mathrm{p}_{\mathrm{j}}}\left(\mathrm{p}_{\mathrm{j}}-\mathrm{p}_{\mathrm{j}}^{\mathrm{k}}\right)+\Theta^{2}
$$

When substituting this last expression into expression [9] and after rearranging some terms, the expression yielding the parameter updates is obtained [11]:

$$
\underline{\Delta p}=\left(\underline{\underline{S}}^{\mathrm{t}} \underline{S}^{-1} \underline{\underline{S}}^{\mathrm{t}}\left(\varepsilon^{\exp }-\varepsilon^{\mathrm{num}}\left(\underline{\mathrm{p}}^{\mathrm{k}}\right)\right)\right.
$$

in which the following elements are:

$\underline{\Delta p}$ : column vector of the parameter updates of $\sigma_{\mathrm{y} 0}, \mathrm{~K}, \mathrm{n}, \mathrm{G}, \mathrm{F}$ and $\mathrm{N}$

$\underline{\varepsilon}^{\exp }: \quad$ column vector of the experimental strains 
$\underline{\varepsilon}^{\text {num }}\left(\underline{p}^{\mathrm{k}}\right): \quad$ column vector of the finite element strains as a function of the different parameters at iteration step $\mathrm{k}$

$\underline{\mathrm{p}}^{\mathrm{k}}: \quad$ the three parameters at iteration step $\mathrm{k}$

$\underline{\mathrm{S}}$ : $\quad$ sensitivity matrix

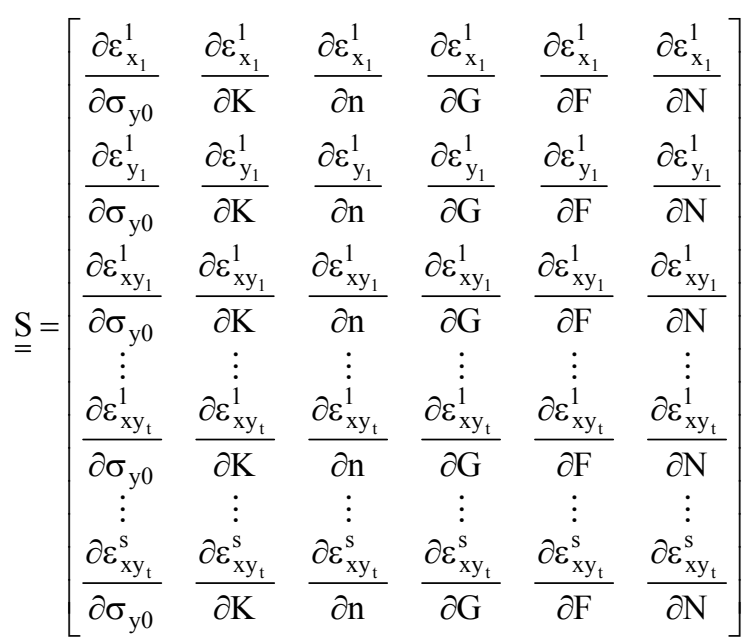

The sensitivity matrix (expression [12]) groups the sensitivity coefficients of the strain components in every element of the FE mesh with respect to the plastic material parameters.

$\frac{\partial \varepsilon_{\mathrm{xy}_{\mathrm{t}}}^{\mathrm{s}}}{\partial \mathrm{n}}$

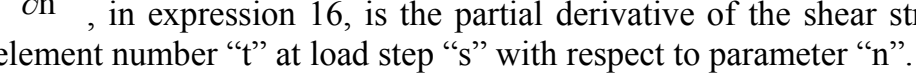

Obviously not the entire set of Gauss points is considered. Only those Gauss points in which the equivalent plastic strain $\varepsilon_{\mathrm{eq}}^{\mathrm{pl}}$ is different from zero are considered. The elements in which plastic deformation at a given load step has not yet occurred, are simply not sensitive to the yield locus and the hardening parameters and are therefore not considered in the sensitivity matrix.

The number of considered Gauss points not only depends on the load step. It is a function of the iteration step as well. When the identification routine is started, the first simulation is performed with a given value of the initial yield stress. The total number of gauss points in which plastic deformation occurs, then depends on the starting value of the pre-strain $\varepsilon_{0}$. If in the next iteration step the value of pre-strain $\varepsilon_{0}$ is updated to e.g. a lower value, then the total number of elements in which $\varepsilon_{\mathrm{eq}}^{\mathrm{pl}}$ is different from zero will increase. This implies that during the identification routine not only the values of the sensitivities change. The size of the sensitivity matrix is subject to a variation as well. 
408 EJCM - 18/2009. Pictures and finite elements

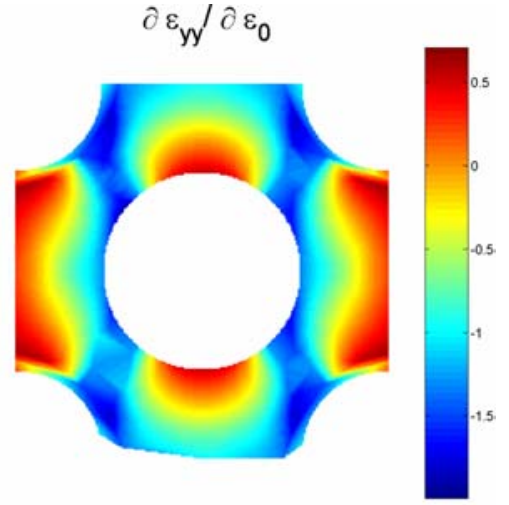

(a)

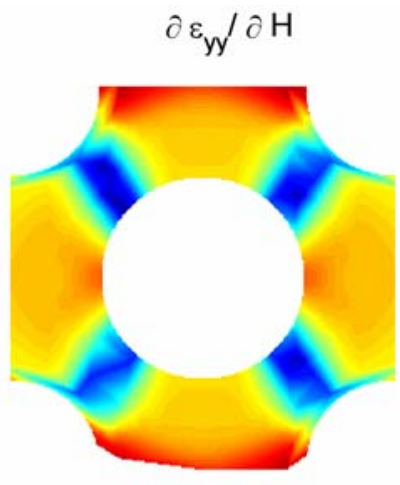

(c)

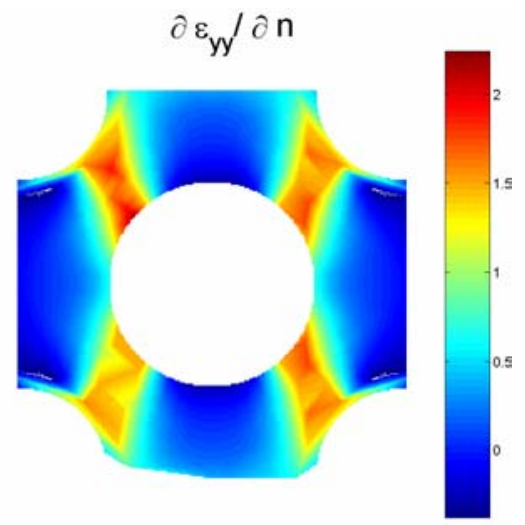

(e)

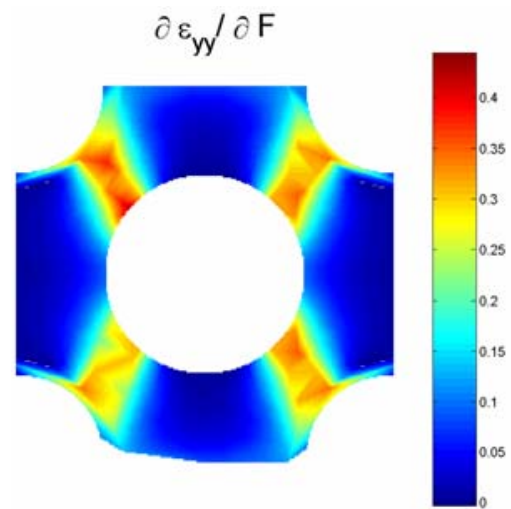

(b)

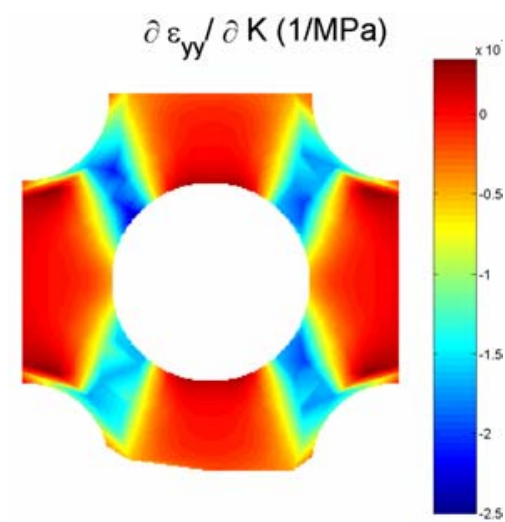

(d)

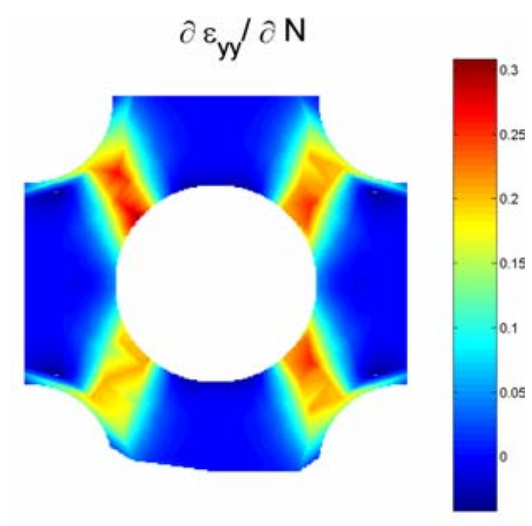

(f)

Figure 7. Plots of the sensitivity of the strain component $\varepsilon_{y y}$ with respect to the 6 unknown parameters for load step 7 


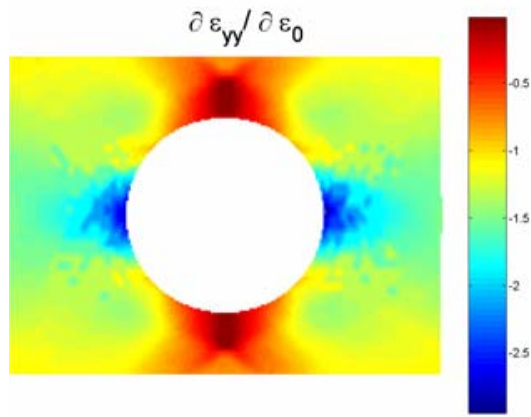

(a)

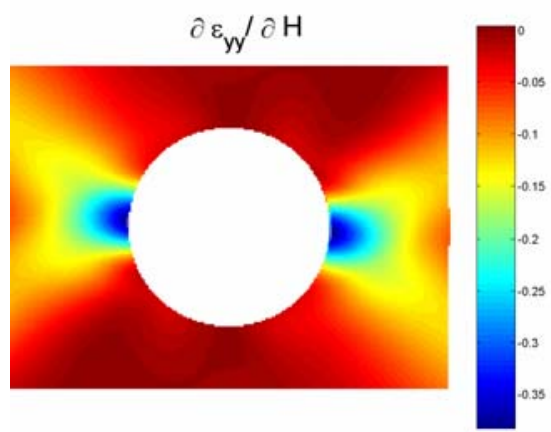

(c)

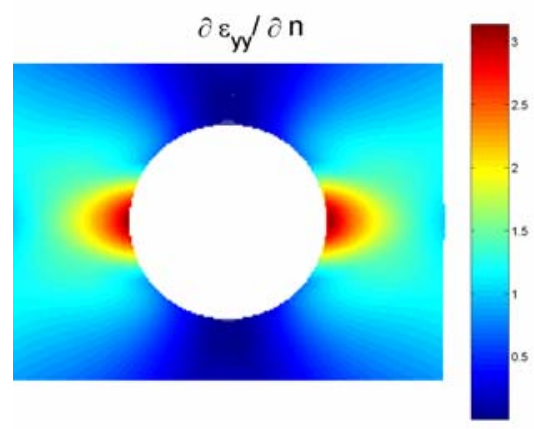

(e)

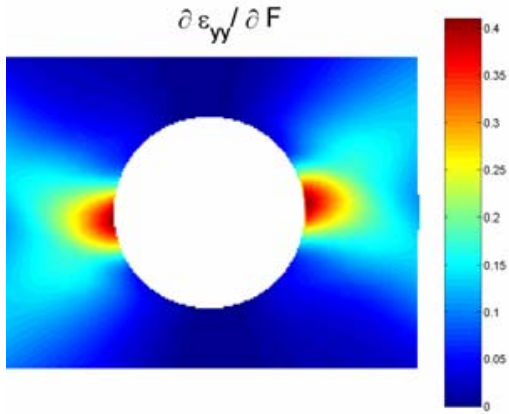

(b)

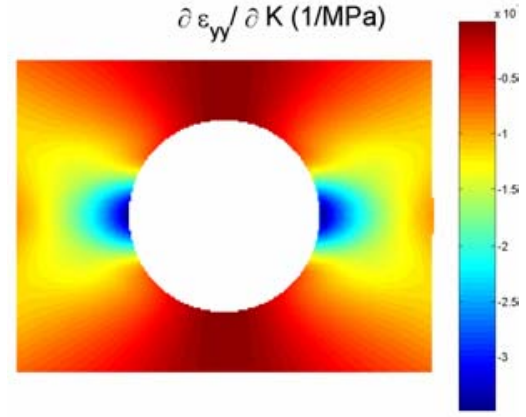

(d)

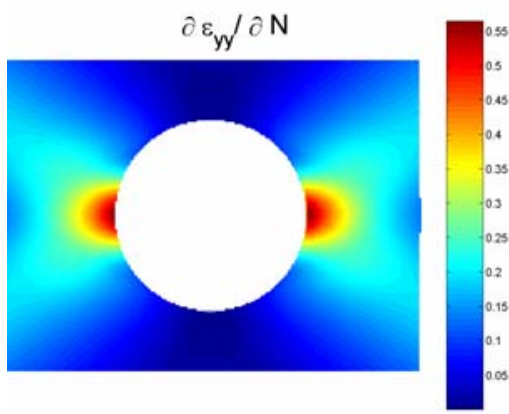

(f)

Figure 8. Plots of the sensitivity of the strain component $\varepsilon_{y y}$ with respect to the 6 unknown parameters for load step 7 


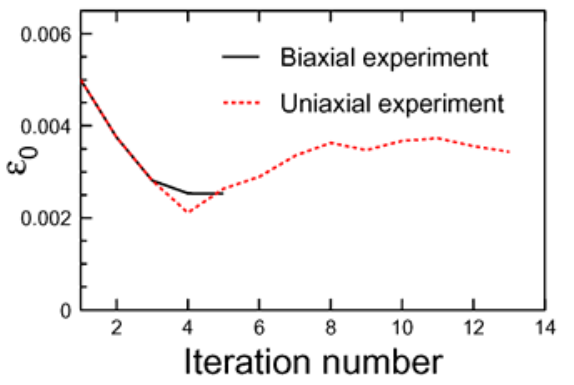

(a)

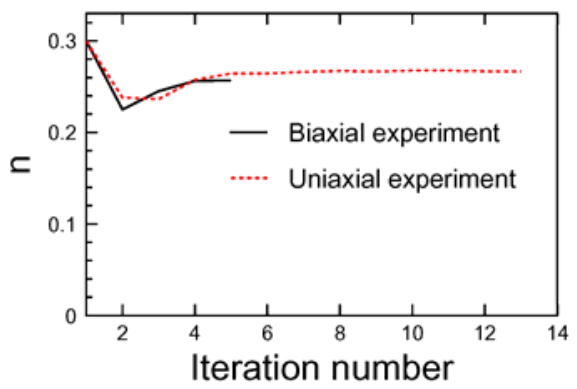

(c)

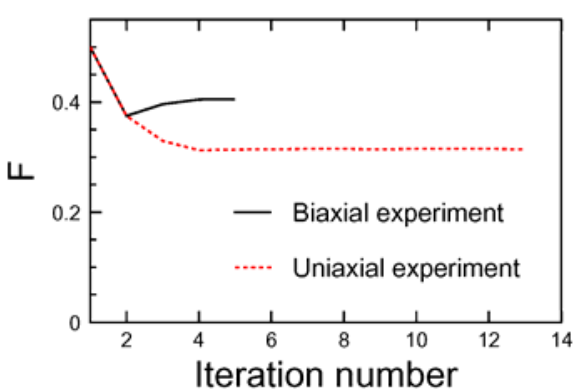

(e)

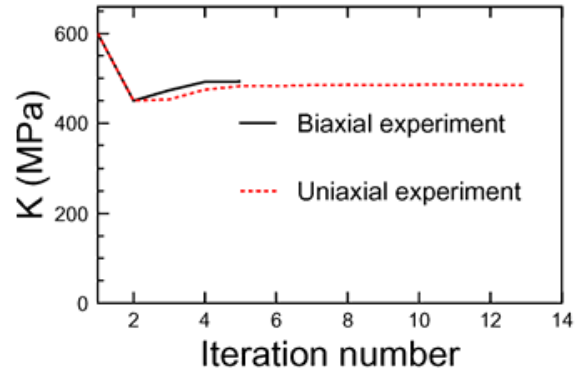

(b)

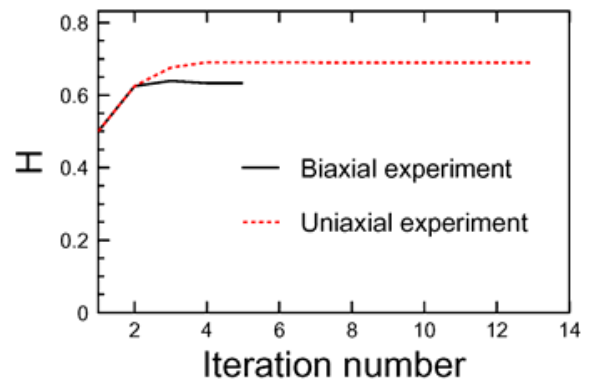

(d)

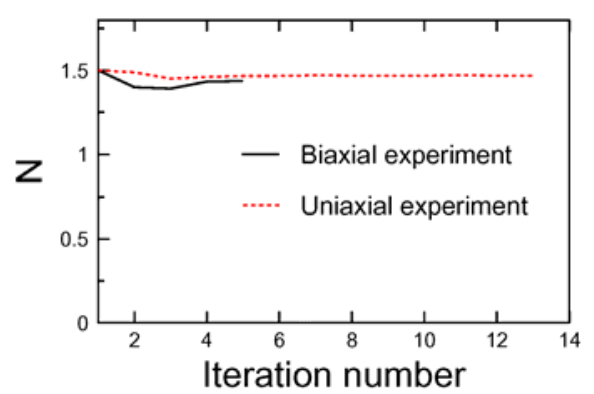

(f)

Figure 9. Convergence plots of the different parameters as a function of the iteration step and the test set-up 
As was already mentioned the sensitivity matrix is computed by means of finite differentiation. As a result each iteration requires 7 FE simulations. Every iteration takes about 1 hour of CPU time. Figures 7(a) to 7(f) and 8(a) to 8(f) show some plote of the sensitivity of the strain component $\varepsilon_{\mathrm{yy}}$ with respect to the six unknown parameters for load step 7

\section{Identification results and discussion}

\subsection{Uni-axial experiment vs bi-axial experiment}

The final parameter values obtained through the inverse method for both the uniaxial and the bi-axial experiments are summarized in Table 1. Figures 9(a) to 9(f) and Figure 10 plot the evolution of the unknown parameters and the result of the cost function during the updating procedure. Figures 11 (a) to 11(f) and 12(a) to 12(f) compare the experimentally measured and the numerically computed strain fields for the biaxial experiment and the uni-axial experiment respectively at the end of load step 7. As one can se, the experimental and the numerical strain fields are very similar.

The results of both tests are quite similar, except for the pre-strain $\varepsilon_{0}$ and the Hill parameter F. This section together with Section 7.2 attempts to explain these differences.

The criterion to end the iterative optimization process is based on the values of the updates for the different material parameters: when the ratio of the value of the updates to the actual parameter values drops below $0.5 \%$ the routine is stopped. It should be mentioned that this criterion is never met in case of the uni-axial test, as can be seen in Figure 7 (a), which plots the evolution of the pre-strain $\varepsilon_{0}$. The value of $\varepsilon_{0}$ keeps varying between 0.00343 and 0.00373 . However, Figure 8 shows that the cost function (red, dashed line) has already converged after about 5 iterations. Thus, the value of the cost function is almost independent of the value of $\varepsilon_{0}$, at least at the current working point. This can probably be explained by the fact that no load steps at initial yielding (i.e. equivalent to small plastic strains) are taken into account in the inverse method. For large strains, the value of the pre-strain $\varepsilon_{0}$ is less important. Since almost no data at initial yielding is available, it is rather hard to determine the pre-strain $\varepsilon_{0}$.

\subsection{Inverse method vs homogeneous test}

The final parameter values obtained through the different identification methods are summarized in Table 1. It should be noted that there is quite some spreading on the values of the Hill parameters obtained through homogeneous identification. The results of the inverse methods and the homogeneous tests are quite similar, except for the pre-strain $\varepsilon_{0}$. This was already explained in the previous section. 


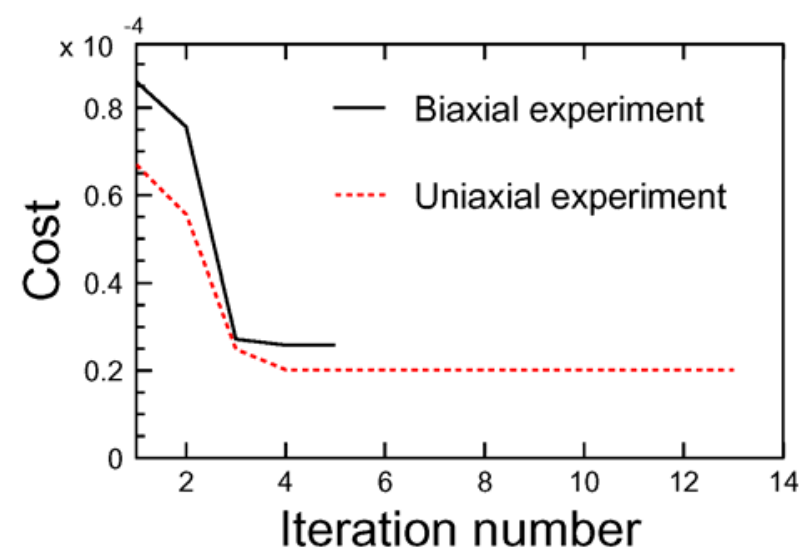

Figure 10. Cost function value as a function of the iteration step and the test set-up

Table 1. Final parameter values obtained through the different identification methods

\begin{tabular}{|c|c|c|c|c|}
\hline \multirow{2}{*}{ Parameter } & \multirow{2}{*}{\multicolumn{2}{|c|}{ Homogeneous tests }} & \multicolumn{2}{|c|}{ Inverse methods } \\
\hline & & & Bi-axial test & Uni-axial test \\
\hline$\varepsilon_{0}$ & \multicolumn{2}{|c|}{0.0063} & 0.00253 & $\begin{array}{c}0.00343- \\
0.00373\end{array}$ \\
\hline K (MPa) & \multicolumn{2}{|c|}{500} & 493 & 486 \\
\hline \multirow[t]{2}{*}{ n } & \multicolumn{2}{|c|}{0.25} & 0.257 & 0.267 \\
\hline & $\begin{array}{l}\text { Stress state } \\
\text { fitting }\end{array}$ & Lankford & & \\
\hline $\mathbf{F}$ & 0.495 & 0.26 & 0.405 & 0.315 \\
\hline $\mathbf{H}$ & 0.505 & 0.665 & 0.633 & 0.69 \\
\hline $\mathbf{N}$ & 1.52 & 1.27 & 1.438 & 1.47 \\
\hline
\end{tabular}

Table 2. Cost function value for both test set-ups using the different sets of identified parameter values

\begin{tabular}{|l|c|c|}
\hline $\begin{array}{l}\text { Parameter Identification } \\
\text { Method }\end{array}$ & Bi-axial experiment & Uni-axial experiment \\
\hline $\begin{array}{l}\text { Homogeneous tests }+ \\
\text { Stress state fitting }\end{array}$ & $13.7 \mathrm{e}-5$ & $3.8 \mathrm{e}-5$ \\
\hline $\begin{array}{l}\text { Homogeneous tests }+ \\
\text { Lankford }\end{array}$ & $16.1 \mathrm{e}-5$ & $11.9 \mathrm{e}-5$ \\
\hline Bi-axial test & $2.5 \mathrm{e}-5$ & $3.5 \mathrm{e}-5$ \\
\hline Uni-axial test & $3.9 \mathrm{e}-5$ & $2.0 \mathrm{e}-5$ \\
\hline
\end{tabular}




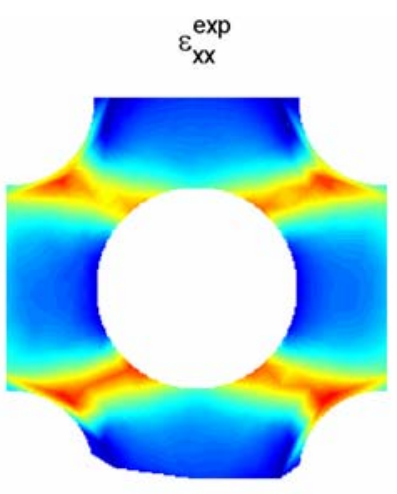

(a)

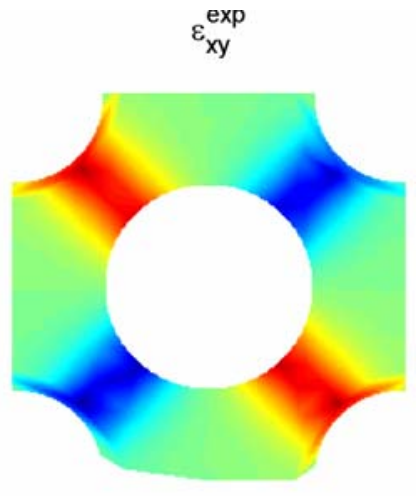

(c)

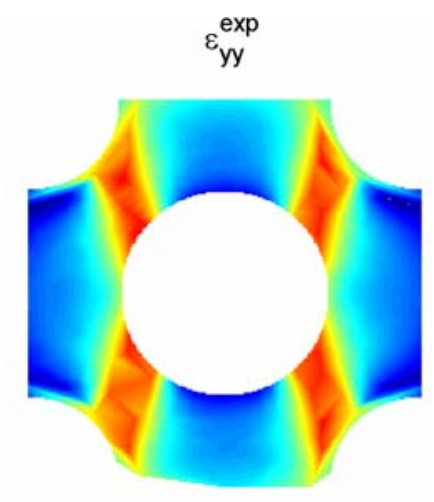

(e)

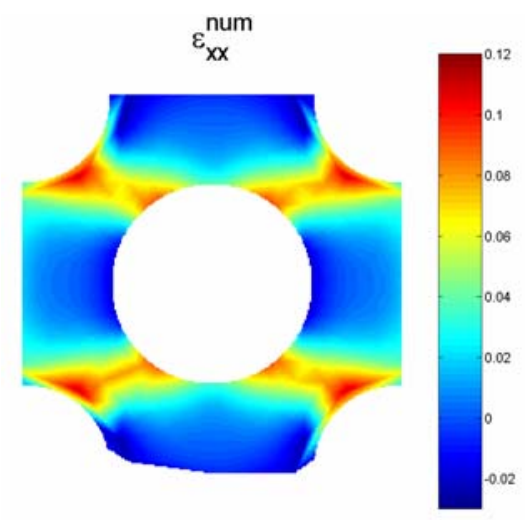

(b)

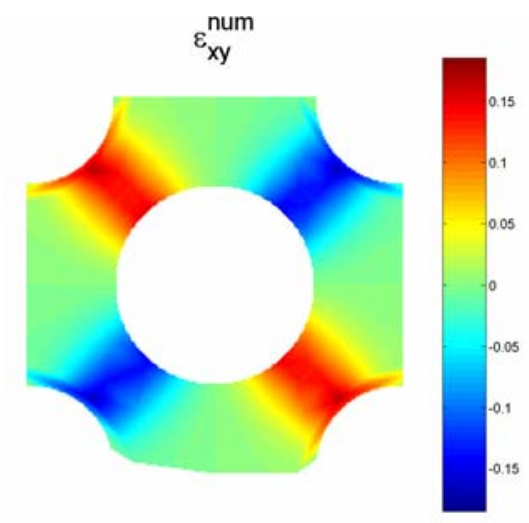

(d)

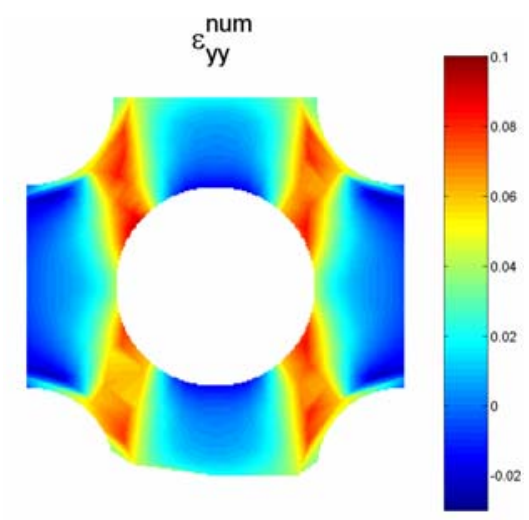

(f)

Figure 11. Comparison of the experimental and the numerical strain fields for the biaxial experiment at the end of load step 7 


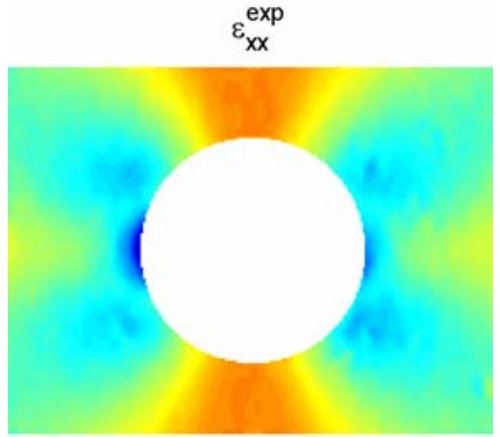

(a)

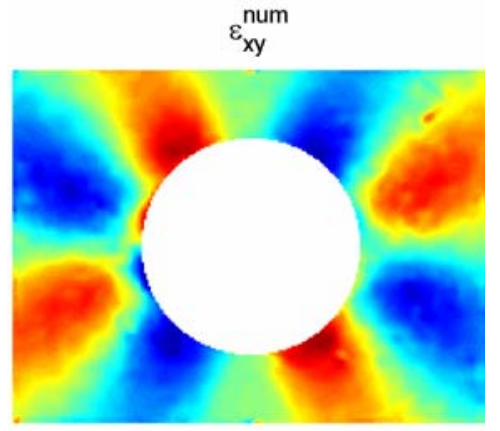

(c)

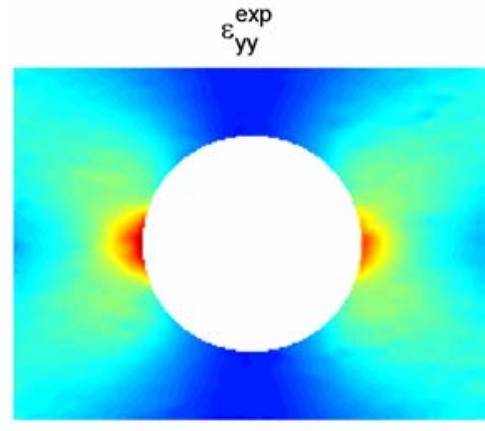

(e)

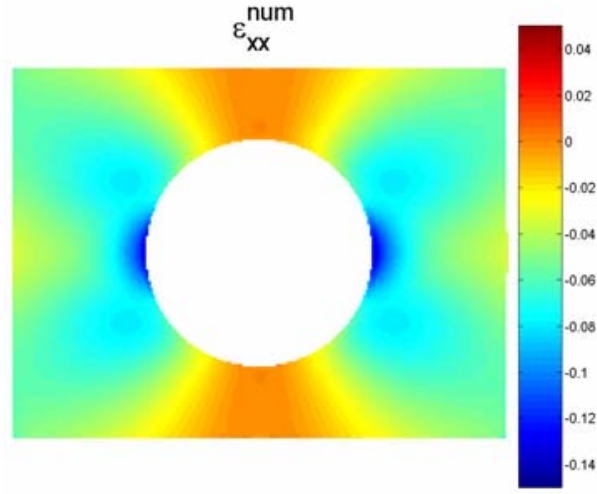

(b)

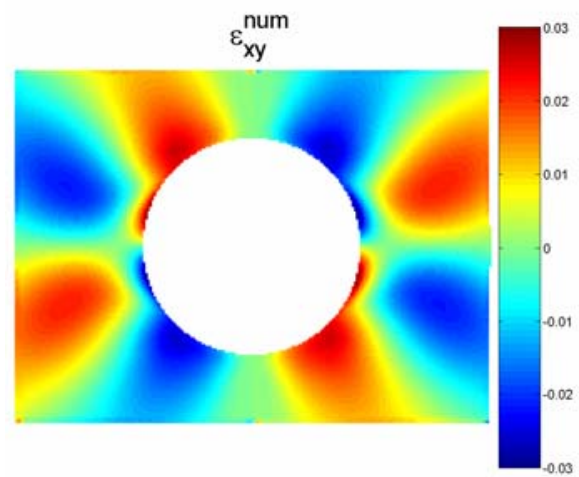

(d)

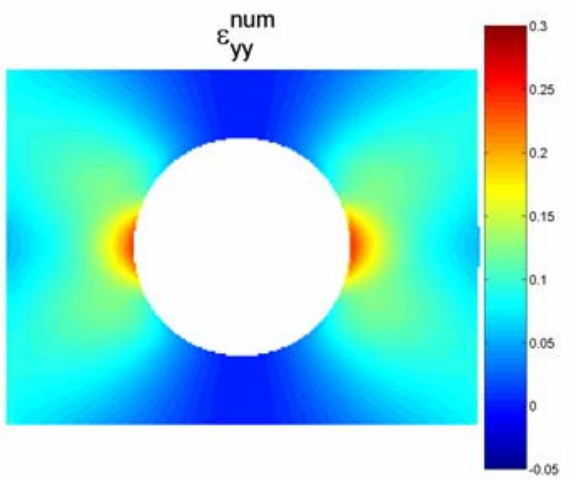

(f)

Figure 12. Comparison of the experimental and the numerical strain fields for the uni-axial experiment at the end of load step 7 
Table 2 gives the value of the cost function for the different sets of parameter values when applying those parameter values to simulate the uni-axial and the biaxial experiment. This table clearly shows that the inverse method does its job well: it determines the optimal parameter values to simulate that particular test. It also shows that the parameter values obtained by the bi-axial and the uni-axial test are rather equivalent: for both experiments these sets of parameter values yield the lowest result for the cost function.

Finally, the inverse method fits the numerical material model to the available (measured) data. Different available strain data will result in different parameter values, because of the fact that the numerical material model does not perfectly describes the real material behaviour. This also explains the differences between the parameter values obtained through the different tests.

\section{Conclusions}

The proposed inverse method allows to determine simultaneously the parameters $\mathrm{F}, \mathrm{H}$ and $\mathrm{N}$ of the Hill 48 yield surface and the parameters $\varepsilon_{0}, \mathrm{~K}$ and $\mathrm{n}$ of the Swift hardening law, based on the strain data available from a uni-axial tensile test on a perforated specimen and based on the strain data available from a bi-axial tensile test on a perforated cruciform specimen.

It has been proven that the results obtained through homogeneous tests not necessarily yield the best results when applying them to a "real" deformation process (i.e. the experiments used in the inverse method). Thus, probably it will be necessary to choose the material test (to identify the unknown material parameters) in accordance with the subsequent deformation processes which have to be simulated.

In the future other material tests will be performed and other material models will be applied. The influence of the number and the spreading of the load steps in the identification process will also be studied.

\section{Acknowledgements}

The authors would like to thank Prof. A.M. Habraken from the University of Liège, Belgium for the input considering the IF DC06 steel and Prof. D. Van Hemelrijck from the Vrije Universiteit Brussel for kindly making the testing equipment available.

\section{References}

Boogaard A. H., Thermally Enhanced Forming of Aluminium Sheet, Twente University, Twente, The Netherlands, 2002. 
Bruck H.A., McNeil S.R., Sutton M.A. and Peters W.H., "Digital Image Correlation using Newton-Raphson Method of Partial Differential Correction", Experimental Mechanics, vol. $29, \mathrm{n}^{\circ} 3,1989$, p. 261-267.

Bruhns O. T. and Anding D. K., "On the simultaneous estimation of model parameters used in constitutive laws for inelastic material behaviour", International Journal of Plasticity, 1999, vol. 15, p. 1311-1340.

Chaudonneret M., Gilles P., Labourdette R., Policella H., « Machine d'essais de traction biaxiale pour essais statiques et dynamiques », La Recherche Aérospatiale, vol. 5, 1977, p. 299-305.

Cheng et al., "Full-field Speckle Pattern Image Correlation with B-Spline Deformation Function", Experimental Mechanics, 42, 2002, p. 344-352.

Chu T.C., Ranson W.F., Sutton M.A. and Peters W.W., "Applications of Digital Image Correlation Techniques to Experimental Mechanics", Experimental Mechanics, vol. 25, $\mathrm{n}^{\circ} 3,1985$, p. $232-244$.

Dawicke D.S., Pollock W.D., Bi-axial testing of 2219-T87 aluminum alloy using cruciform specimens, Nasa Contractor Report 4782, 2000, p. 1-46.

Flores P., Development of experimental equipment and identification procedures for sheet metal constitutive laws, $\mathrm{PhD}$ thesis, University of Liège, 2006.

Gavrus A. and Massoni E. and Chenot J. L., "An inverse analysis using a finite element model for identification of rheological parameters," Journal of Materials Processing Technology, 1996, vol. 60, p. 447-454.

Grediac M., Pierron F., "Applying the virtual fields method to the identification of elasto-plastic constitutive parameters", International Journal of Plasticity, vol. 22, 2006, p. 602-627.

Kajberg J. and Lindkvist G., "Characterisation of materials subjected to large strains by inverse modelling based on in-plane displacement fields", International Journal of Solids and Structures, vol. 41, $\mathrm{n}^{\circ} 13,2004$, p. 3439-3459.

Khalfallah A., BelHadjSalah H., Dogui A., "Anisotropic parameter identification using inhomogeneous tensile test”, European journal of Mechanics A/Solids, 21, 2002, p. 927-942.

Knauss W.G., Chasiotis I., Huang Y., "Mechanical measurements at the micron and nanometer scales", Mechanics of materials 35, 2003, p. 217-231.

Lam Y. C. and Khoddam S. and Thomson P. F., "Inverse computational method for constitutive parameters obtained from torsion, plane-strain and axisymmetric compression tests", Journal of Materials Processing Technology, 1998, vol. 83, p. 62-71.

Lecompte D., Smits A., Sol H., Vantomme J., Van Hemelrijck D., "Mixed numericalexperimental technique for orthotropic parameter identification using biaxial tensile tests on cruciform specimens", International Journal of Solids and Structures 44, 2007, p. $1643-1656$.

Lecompte D., Elastic and Elasto-Plastic material parameter identification by inverse modelling of static tests using digital image correlation, $\mathrm{PhD}$ thesis, Vrije Universiteit Brussel, 2007. 
Mahnken R. and Stein E., "A unified approach for parameter identification of inelastic material models in the frame of the finite element method", Comput. Methods Appl. Mech. Eng.,1996, vol. 136, p. 225-258.

Mahnken R., "Aspects on the finite-element implementation of the Gurson model including parameter identification," International Journal of Plasticity, vol. 15, 1999, p. 1111-1137.

Mahnken R. and Stein E., "Parameter identification for finite deformation elasto-plasticity in principal directions”, Comput. Methods Appl. Mech. Eng., 1997,vol. 147, p. 17-39.

Makinde A., Thibodeau L., Neale K.W., "Development of an apparatus for bi-axial testing using cruciform specimens", Experimental mechanics, vol. 32/2, 1992, p. 138-144.

Meuwissen M., An Inverse Method for the Mechanical Characterization of Metals, Ph.D. thesis, Eindhoven University of Technology, Netherlands, 1998.

Pannier Y., Avril S., Rotinat R., Peirron F., "Identification of elasto-plastic constitutive parameters from statically undetermined tests using the virtual fields method", Experimental Mechanics, vol. 46/6, 2006, p. 735-755.

Peters W.H. and Ranson W.F., "Digital imaging techniques on experimental stress analysis", Optical Engineering, vol 21, n 3, 1982, p. 427-431.

Schreier H.W., Braasch J.R., Sutton M.A., "Systematic errors in digital image correlation caused by intensity interpolation", Optical Engineering, vol. 39, n 11, 2000, p. 2915-2921.

Smits A., Van Hemelrijck D., Philippidis T.P. and Cardon A., "Design of a cruciform specimen for biaxial testing of fibre reinforced composite laminates", Composites Science and Technology, vol. 66, $\mathrm{n}^{\circ}$ 7-8, 2006, p. 964-975.

Springmann M. and Kuna M., "Identification of material parameters of the GursonTvergaard-Needleman model by combined experimental and numerical techniques", Computational Materials Science, vol. 32, 2005, p. 544-552.

Sutton M.A., Wolters W.J., Peters W.H., Ranson W.F. and McNeil S.R., "Determination of Displacements using an Improved Digital Correlation Method", Image Vision Computing, vol. $1, \mathrm{n}^{\circ} 3,1983$, p. 133-139.

Sutton M.A., Cheng M., Peters W.H., Chao Y.J. and McNeil S.R., "Application of an Optimized Digital Image Correlation Method to Planar Deformation Analysis", Image Vision Comp., vol. 4, n 3, 1986, p. 143-150.

Sutton M.A., McNeil S.R., Jang J. and Babai M., "The Effect of Subpixel Image Restauration on Digital Image Correlation Estimates", Optical Engineering, vol. 27, n 10, 1988, p. $870-877$.

Vegter H., Ten Horn C. et al., "Characterization and modelling of the plastic material behaviour and its application in sheet metal forming simulation", Proceedings of COMPLAS VII, Barcelona, 2003.

Yoneyama S., Kikuta H., Kitagawa A. and Kitamura K., "Lens Distortion Correction for Digital Image Correlation by Measuring Rigid Body Displacement”, Optical Engineering, vol. $45, n^{\circ} 2,2006$, p. 1-9. 
Yoshidaa F., Urabe M. et al., "Inverse approach to identification of material parameters of cyclic elasto-plasticity for component layers of a bimetallic sheet", International Journal of Plasticity, 2003, vol. 19, p. 2149-2170.

Zouani A., Bui-Quoc T., Bernard M., "A proposed device for bi-axial tensile fatigue testing, Fatigue and Fracture”, ASME PVP-323, vol. 1, 1996, p. 331-339. 